\title{
120 \\ Practical GUI Screen Design: Making It Usable
}

\author{
Cliff Wilding
}

\author{
PO Box 312 \\ Prahran VIC 3181 \\ AUSTRALIA \\ cliffw@mel.hiser.com.au
}

\begin{abstract}
There is much more to designing usable GUI screens than making them look good. The way a screen looks should tell the user how to interact with it, and what behaviour to expect. Screen design is about visual communication, the bridge between the look and the feel of the user interface. In this full day tutorial you will examine the principles of good screen design, including a detailed examination of screen layout, templates and metaphors.

The tutorial provides a clear understanding of how to take advantage of user knowledge when creating screen designs that work. Examine layout techniques, including colour, fonts and symbols, and learn the principles of creating easyto-use software and interactive new media productions. The tutorial is very much hands-on with exercises - you will put the skills you learn into practice.
\end{abstract}

Learn valuable tips and techniques for the best ways to use icons, controls, text and graphics in user interfaces.

KEYWORDS user interface, design, screen design, interaction design, user-centred design

\section{Overview}

With the proliferation of graphical user interfaces (GUIs) many issues and problems have arisen regarding their design, in particular the design of GUI screens. In essence, screens enable the dialog to take place between the user and the system. Failure to communicate clearly results in an application that is difficult to use. This is primarily due to the plethora of widgets and objects that are now available. The variety of screen elements means that there is an infinite number of combinations possible and consequently many decisions to be made. Making the best decisions and trade-offs for a specific application and particular instance is often difficult and requires GUI design skills and knowledge. Adhering to standards adds to the complexity.

Screen design for GUIs not only encompasses the selection and layout of widgets and objects, but extends to the behaviour of those widgets and the way in which users interact with the interface. Screen design covers both the visual and behavioural aspects of a GUI; the design of both requires close attention to ensure usability. Practical GUI Screen Design is a one day tutorial that covers many aspects of GUI design pertinent to screen design.

The tutorial is highly visual, with many examples of both good and bad screen design. Each point is illustrated, described and discussed, giving the tutorial a "real world" feel. You will also learn valuable tips 
and techniques for the best ways to use icons, controls, text and graphics in user interfaces.

Your instructor is a User Interface Design Consultant, with several years experience designing user interfaces for corporate and home applications.

The tutorial is aimed at systems analysts and designers, business analysts, software developers, multimedia developers, visual design managers and computer-based training authors. It is an advantage if attendees are familiar with GUIs and/or GUI design.

\section{Topics Covered In This Tutorial}

- Introduction

- User Interface Design

- Basic GUI Concepts

- Anatomy of a Window

- Windows

- Templates

- Metaphors

- Screen Elements

- Cursors

- Layout \& Design

- Visual Harmony

- Clarity and Communication

- Providing Functional Clues Visually

- Colour

- Graphical Elements

- Typography

- Language

- Wrap Up

\section{Biography of the Presenter}

Cliff Wilding is a User Interface Design Consultant with The Hiser Group, based in Melbourne, Australia.

Since joining The Hiser Group in 1994, Cliff has worked on numerous projects, performing analysis, design and usability testing tasks for organisations such as Telstra, BHP, Commonwealth Bank, Heath Insurance, the Royal Australian Air Force, Unisys, Woolworths and Wooden Eye Multimedia. These projects involved techniques such as contextual inquiry, user analysis, collaborative design, paper prototyping, usability testing, style-guide development and expert evaluation of user interfaces.

Cliff has extensive project management experience, and has also developed several electronic prototypes of user interface designs. He also teaches user interface design in The Hiser Group's course "User Interface
Screen Design - Making it Usable", and has presented papers and workshops at $\mathrm{OzCHI} 96$.

Following his graduation from the University of Melbourne, Cliff began his career with Disctronics Limited as a software engineer in the first team in Australia to produce a CD-ROM. Here he was responsible for designing and implementing successful CD-ROM information retrieval products.

Following his tenure at Disctronics, Cliff spent three years with INFO-ONE International, Australia's leading on-line and CD-ROM database developer and publisher. As Software Development Manager, he was responsible for designing and managing the implementation of information retrieval systems for clients including Dun \& Bradstreet, Australian Stock Exchange, CSIRO, Department of Defence, NSW State Library, and NRMA.

Cliffs holds a degree in Computer Science (Hons. first class) from the University of Melbourne.

\section{Timetable}

Time Length Activity

9:10 40

9:50 15

1. Introduction

10:10 25

$10: 30 \quad 15$

2. Anatomy of a Window (Windows)

$11: 00 \quad 20$

2. Anatomy of a Window (Templates)

Morning Tea

$11: 20 \quad 30$

2. Anatomy of a Window (Metaphor)

$11: 50 \quad 20$

Detective Exercise

$12: 10 \quad 20$

$12: 30 \quad 60$

$1: 30 \quad 30$

2:00 30

$2: 30 \quad 30$

3:00 15

Detective Exercise Presentations

2. Anatomy of a Window (Elements)

Lunch

Sofa Touchscreen Exercise

Sofa Touchscreen Presentations

3. Layout and Design

$3: 30 \quad 15$

$4: 00 \quad 40$

$4: 30 \quad 20$

$4: 45 \quad 15$

5:00
Afternoon Tea

3. Layout and Design (cont.)

Elvis Activity

Video \& Questions

Finish
Elvis Activity Presentations 